\title{
Anthropological Perspective in HR Management: A Case Study of China-based Multi-national Corporation
}

\author{
Yan Yan \\ Beijing Jiaotong University
}

Chinese companies encounter many cross cultural management problems when globalize their market. With an anthropological perspective, this empirical research taps various information by getting familiar with the people within the organization studied, and explores how organizational identification (OID) affects employees' performance in a cross culture scenario. The research conclusion shows that OID will affect employee's work behavior and attitude in a positive way and hence improve team performance. In the final part of the study, some cross culture management issues are discussed and advices based on the study are presented.

\section{THE QUESTION}

Along with their development and expansion in the global market, the China-based Multi-national corporations (CB-MNC) need to recruit local staff all over the world; at the same time, more and more Chinese expatriates are sent to different countries. As the consequence, cross-culture management issues emerge.

The researcher carried out a cross-culture research since 2007 in a large CB-MNC. From 2007 to 2008, the researcher visited over 1600 local staff over 23 countries. Basing on the field work as well as second-hand document analysis, the researcher identified five top issues/problems in the cross-culture management of the CB-MNC studied: distrust among Chinese and local staff, disqualification of language of expatriates, lack of cross-culture training, inconsistent corporate image in oversea offices and Headquarters, short of information and understanding on company's brand, mission and target.

Among the five issues, the first three have been studied and discussed in abundant cross culture researches, which will not be included in this research. The later two are the focuses of this research, which are all related with the employees "perception of their roles and identity" in the organization. Lacking of clarity and understanding of corporate image, strategy and job roles etc. may result in negative impact on employees' work attitude and behavior. Thus, this research aims at finding out how employees' identification are affected by the factors above and then providing advices on how to improve cross culture management basing on the empirical research.

\section{THEORETICAL BACKGROUND AND RESEARCH METHOD}

\section{Theoretical Background}

Traditional cross culture researches generally take a "cultural" perspective. Thus, these studies try to identify the "differences" caused by different cultures and find out solutions for these differences 
accordingly. However, debates are abundant on the cross culture research conclusions due to the vagueness of the definition of "Culture". (Roberts, 1970; Usunier, 1998).

There are three major problems regarding current cross culture researches. First of all, considering cultural value of groups the same as national cultural value is not justified; second, interactions among groups of different cultures may lead to changes of value of group members; and finally, the personal characters of group members may affect cultural value of group members. (Kirkman, et al. 2001). Even the most influential theoretical framework developed by Hofstede (Hofstede, 1980) are questioned for outdated data, simplification of culture value and inadequacy of research data (Sivakumar and Nakata, 2001).

Considering the deficiency of quantitative methods in studying cross culture management, the researcher adopts anthropological theories and methods in this study in the hope that culturally appropriate ways of doing business can be found. (van Marriewijk, 2010; Tian, 2010)

This research focuses on "identifying the similarity of employees from different cultures" instead of "finding out differences between employees from different cultures". With an anthropological perspective, the study taps various sources of information by getting to know the people within the Organization (Jordan, 2003 and 2010) and explores how organization identification affects employees' work attitude and behavior.

There are numbers of definitions on organizational identification (OID) since the focuses of researchers are diversified. (Stryker and Serpe, 1982; Ashforth and Mael, 1989; Cheney, 1983; Dutton, et al, 1994; Tajfel, 1982). However, all the theories define OID as "a member defines himself or herself by the same attributes of other individual or group". In other words, when an individual integrates his/her belief of organization together with self, OID is consequently formed. (Pratt, 1998).

Many researchers assume that formation of OID is based on "Identity comparison of group members"

(Burke, 1997; Dutton and Dukerich, 1991; Reger et al, 1994; Whetten et al, 1992; Gallois, et al., 2001 ) ; In other words, the result of "Identity Comparison" of group members will affect their behaviors and attitude towards their organization. The higher the level of congruence resulting from this identity comparison process, the higher the level of the members' OID (Forman and Whetten, 2002).

Basing on above theoretical analysis, this research proposes the following OID-Team performance model:

\section{Research Design and Method}

\section{Research Design Framework}

The research starts from a thorough literature review on cross-cultural management and OID. The researcher finds out that even though lots of advancements have been achieved, there are rooms for improvement in the field of cross-cultural management and OID researches. On one side, the traditional "culture-based" cross-cultural management researches are framed by Hofstede's prominent theory in both theoretical and methodological aspects; on the other hand, original Chinese OID theory is in urgent need since existing OID researches are all confined by western theories and researches. To contribute to abovementioned research deficiency, this research tries to establish an OID model based on "Identity congruence", then further explore how OID will affect the performance of cross-culture teams.

This empirical research consists of three major stages. Since there isn't any established instrument for measuring "identity-based OID", in the first stage, the researcher needs to develop the instrument with grounded theory. This is one of the theoretical innovation as well as a huge challenge for the research. Basing on abundant literature review, in-depth interview with managers and exploratory and confirmatory factor analysis with large samples, the researcher develops an "Identity-based OID" with three factors: the transformational, transactional and human-centered factors. 


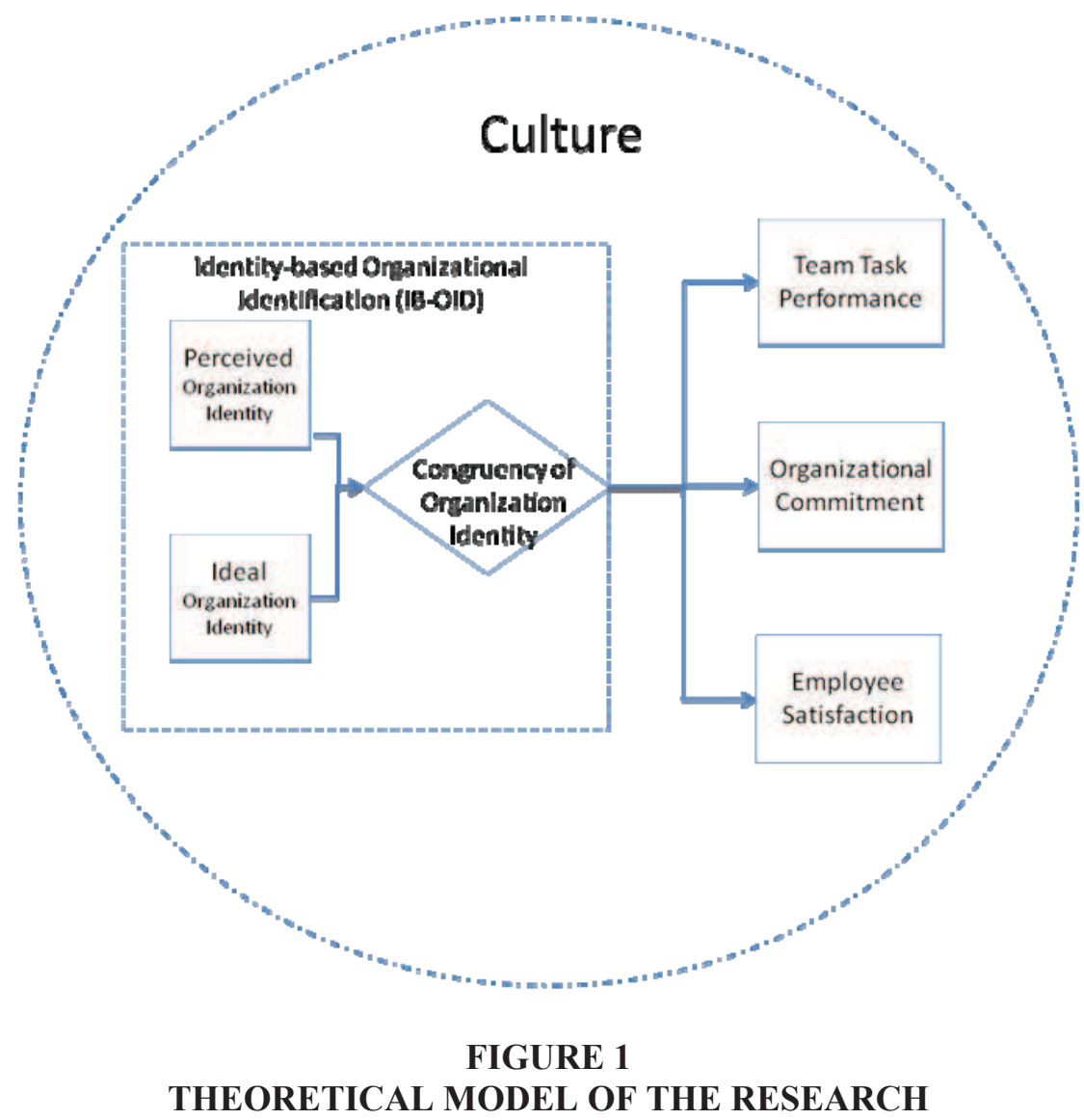

In the second stage, statistical method is applied to explore the relationship between OID and such dependent variables as Team Task Performance, Organizational Commitment and Employee Satisfaction. The research conclusion indicates that the higher the consistency of Perception and Expectation of employees idea/feeling of such aspects of the organization as corporate image, internal management and career development etc., the higher the OID of the employee, and hence the higher the employees' performance, commitment and satisfaction.

Qualitative method is deployed to provide further proofs on the OID-Team performance model in the third stage. Moreover, the mechanism of the research model is explored and new findings also emerged in this stage.

The research adopts quantitative as well as qualitative research methods. Semi-structured interview and grounded theory are adopted in developing the "Identity-based OID" instrument. To explore the OIDTeam Performance model, large samples are deployed in the quantitative research, while Focused Interview is applied in the qualitative research.

Identity-based Organizational Identification (IB-OID)

To develop the instrument of IB-OID, semi-structured interview is applied. In the research, 6 senior managers and 36 middle level managers are interviewed, covering the managerial positions in sales, marketing, R\&D, Human resource, and finance etc. The interview of 42 key informants is carried out by four interviewers who are responsible for the whole process, including making appointment, carrying out interview, data processing and analysis and final report writing. Basing on the data collected from the interview, grounded theory is deployed to identify the factors of organization identity of the studied CBMNC. 
After the qualitative research, quantitative method is adopted to validate the IB-OID instrument. Two rounds of survey are carried out for exploratory and confirmatory factor analysis. Tools for data analysis are SPSS and AMOS respectively.

The exploratory research covers 300 Chinese and foreign staffs all over the world (200 Chinese and 100 Foreigners). Total 175 feedbacks are collected, with a feedback rate of 56.3\%, among which 143 are from Chinese and 32 from foreigners.

The confirmatory research covers 1200 Chinese and foreign staffs ( 800 Chinese and 400 Foreigners). Total 674 valid feedbacks are collected, with a feedback rate of 57\%, among which 491 are from Chinese and 183 from foreigners.

There are over 100 oversea sales offices and subsidiaries in the CB-MNC studied. The quantitative research covers 64 of the branches which have 50 or above employees. The 183 feedbacks from foreign staff cover 48 countries.

The IB-OID instrument consists of 30 items. Basing on the Burke-Litwin model, the 30 items are categorized into three factors: the Transformational factor, Transactional factor and Human-centered Factor. Transformational factor generally refers to such factors that interact with environmental forces as external environment, leadership, mission, and strategy; Transactional factor generally refers to such factors affected by short-term, day-to-day, reciprocity among people or groups as management practices, structure and procedure; while Human-centered factor involves such factors related to individuals as motivation, individual skills and abilities etc. (Alexander, 2001).

For both Perceived Organization Identity (POI) model and Ideal Organization Identity (IOI) model, GFI, AGFI, CFI, TLI, RMR and RMSEA are applied to evaluate goodness of fit. All of the parameters are above 0.90 , with $\times 2 / \mathrm{df}<5$, indicating a reasonably good model fit. The degrees of reliability of two models are 0.959 and 0.979 respectively. (Yan Yan, 2011)

\section{Conclusions of Quantitative Research}

\section{The IB-OID-Team Performance Model}

In the research, the congruence between POI and IOI is measured by the Absolute value of the difference between POI and IOI; while Team Performance is adopted as the dependent variable, which consists of three variables: Team Task Performance, Organizational Commitment and Employee Satisfaction.

According to data collected, POI and IOI are both positively correlated with the three dependent variables (Team Task Performance, Organizational Commitment and Employee Satisfaction); OIgap (Absolute value of the difference between POI and IOI) is negatively correlated with dependent variables (in other words, the Identity-based Organizational Identification is positively correlated with the dependent variables).

As for control variables, Gender and Education are not correlated with dependent variables; Age is negatively correlated with dependent variables; Tenure is negatively correlated with Team Task Performance and Organizational Commitment at the 0.05 level while with Employee Satisfaction at the 0.01 Level; Nationality is not correlated with Team Task Performance while negatively correlated with Organizational Commitment and Employee Satisfaction.

\section{The Differences between OID of Chinese and Foreign Employees}

There is no significant difference between Chinese and Foreign employees regarding Ideal Organization Identity as well as the Ideal TF, IF and HF; while there are significant difference between Chinese and Foreign employees regarding Perceived Organization Identity as well as the Perceived TF, IF and $\mathrm{HF}$.

The above findings indicate that both Chinese and foreign employees' ideas on "What the company should be" are the same while their perceptions on "What the company is now" are different. 
TABLE 1

THE DIFFERENCES BETWEEN CHINESE AND FOREIGN EMPLOYEES

\begin{tabular}{lccccc}
\hline & $\mathrm{t}$ & $\mathrm{df}$ & $\begin{array}{c}\text { Sig. (2- } \\
\text { tailed) }\end{array}$ & $\begin{array}{c}\text { Mean } \\
\text { Difference }\end{array}$ & $\begin{array}{c}\text { Std. Error } \\
\text { Difference }\end{array}$ \\
\hline & & & & & \\
Perceived TF & 1.873 & 366.159 & .062 & 0.13 & 0.07 \\
Ideal TF & .301 & 357.197 & .764 & 0.02 & 0.07 \\
Perceived IF & 2.353 & 355.571 & .019 & 0.21 & 0.09 \\
Ideal IF & 2.229 & 337.569 & .027 & 0.16 & 0.07 \\
Perceived HF & 4.712 & 337.270 & .000 & 0.36 & 0.08 \\
Ideal HF & .375 & 342.373 & .708 & 0.03 & 0.07 \\
Perceived OI & 3.252 & 362.903 & .001 & 0.23 & 0.07 \\
Ideal OI & 1.033 & 347.125 & .302 & 0.07 & 0.07 \\
\hline
\end{tabular}

Equal variances not assumed

Note: Transformational Factor (TF); Interactive Factor (IF); Human-centered Factor (HF).

\section{Conclusions of Qualitative Research}

To find out the reasons why Chinese and foreign employees' ideas on "What the company is now" are different, the researcher continues on a qualitative research.

In the qualitative research, Focused Interview is adopted to collect data from 13 key-informants. In the interview, the key-informants are required to answer the questions from a retrospective way.

In the focused interview, the researcher identifies three major aspects where foreign employees are different from Chinese employees. The three aspects are: the source of formation of OID, the job role confusion, and the experience of training and career development. In addition, the research uncovers that leadership also affects the formation of OID.

\section{Sources of Formation of OID}

There are two major sources for the formation of OID: external source and internal source. External sources are such factors as company brand, company image and company's position in the industry or society; while internal factors include corporate culture, the provisions of the organization to the members, and the influence of groups/organization on members etc. (Morgan, M. J. et al. 2004) .

During the interview, the researcher discloses that both the external and internal sources are found in the formation of Chinese employees' OID; while only internal sources are found in the formation of foreign staff's OID.

In particular, the sources of Chinese employees' formation of OID include the company's brand, image and position in the industry as well as training and development etc.; while the sources of foreign employees' formation of OID are limited within such company provisions as training, promotion, office environments and sub-culture of groups etc.

\section{The Job Role Confusion}

Once enters a new job position, a quick understanding of tasks and targets from the organization is to the benefit of clarifying employees' "Role Identity", which further strengthens employees' willingness to stay in the organization. Ashforth and Meal (1989) considered that once a strong "role identity" is formed, the member will establish his/her organizational identification with the organization.

In the process of the interview, almost all foreign interviewees mentioned about their perplexing on their job roles and responsibilities. In contrast, no Chinese employee has the same confusion except one Chinese staff which is a new employee just graduated from university.

(OID is changed) since my job role in the company is changed. For the first 
two years I entered the company, there is no clear job responsibility for me. Then, I started to join some projects and I gradually found my position in the job. My second manager provided me the chance to grow. She gave me important assignments in the job and I was successful in these assignments. I rely on the company now. I know many jobs in the branch office are done by me, instead of by others. The company is my company. Now I have a pretty high OID with the company, and the OID keeps going stronger. (20120914UAE-0011)

To better understand foreign employees' job role confusion, we may learn from Hofstede's cross culture value framework.

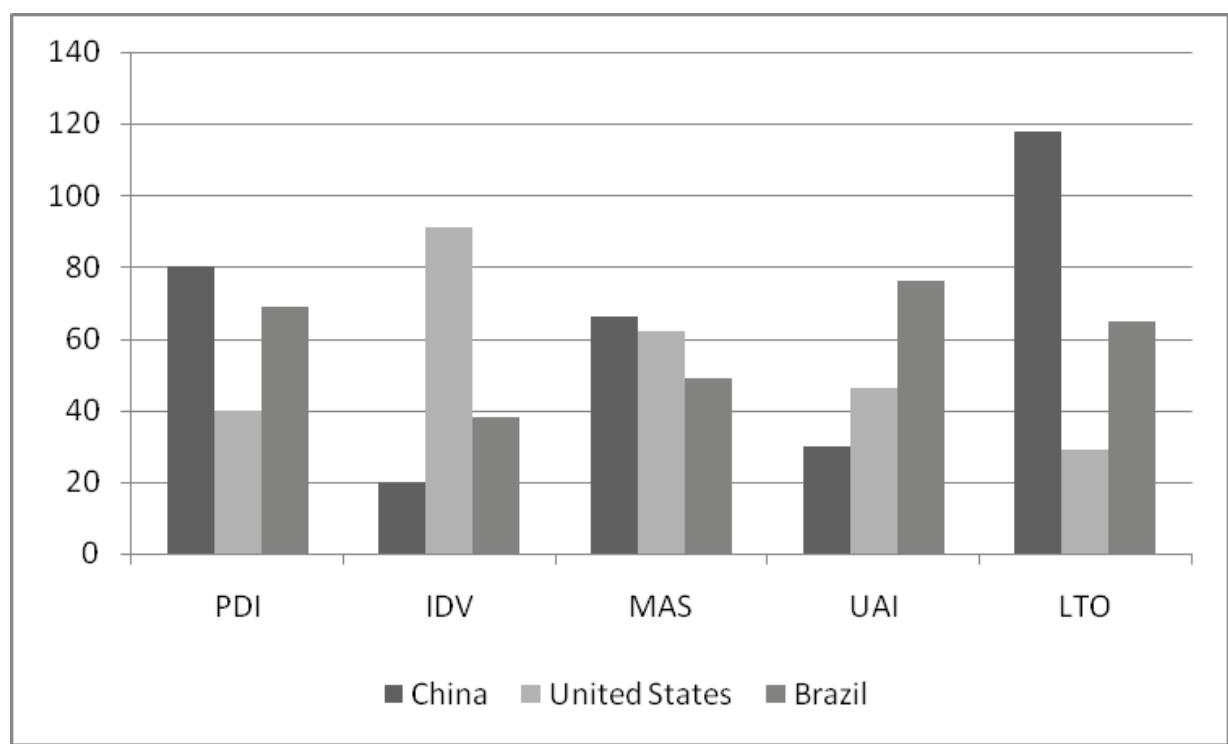

FIGURE 2

UAI OF CHINESE, AMERICAN AND BRAZILIAN

According to Hofstede, comparing to other nations, Chinese's score on UAI (Uncertainty Avoidance Index) is much lower. As indicated in Figure 2, the UAI for Chinese is 30, while 46 for American and 76 for Brazilian. The lower the UAI score, the less tendency to avoid uncertainty. In other words, in a scenario where job responsibility, job target and job role are unclear, Chinese employee will be much more adaptive comparing to people from other cultures.

In practice, in an organization where internal management regulations and information flow are unclear and not effective, the impact on Chinese staff may not be a problem. However, this situation will be destructive for many foreign employees since it is difficult for them to understand their job responsibilities, job targets and necessary information and tools for accomplishing their tasks.

From the data collected, the researcher finds out that the confusion of Job Role has strong negative effect on foreign employees' work attitude and productivity.

\section{Training and Career Development}

A member will relate to an organization through the formation of a Provider-recipient relationship with the organization. In Morgan's (2004) empirical research, such factors as financial, social and career development affect the formation of members' OID.

When exploring the formation of OID in the interview, both Chinese and Foreign employees mentioned about training and development. However, more foreign employees are concerned with 
training and development than Chinese. In particular, four out of five foreign employees and two out of eight Chinese employees mentioned about how training and development are influential in their formation of OID.

\section{Leadership affects Team Performance}

In the interview, many interviewees mentioned about their direct reports when talking about their team task performance, organizational commitment and job satisfaction, which indicates that leadership plays an important role on work attitude and behavior of employees from different cultures.

To summarize, there are differences on the source of formation of OID, job role confusion, and experience of training and career development between Chinese and Foreign employees. These findings provide valuable information for making advices on effective cross culture management.

\section{ADVICES ON CROSS CULTURE MANAGEMENT}

As the conclusions of this research indicates, foreign staff's understanding of corporate image, brand, and culture is poor since CB-MNC's brand publicity, industry position in the global market are weak. At the meantime, the internal management procedure and regulations lag behind the fast market expansion of CB-MNC, which leads to foreign employees' confusion on job responsibilities and job targets. Finally, due to cost strategy and poor global management system, employees of CB-MNC are mainly Chinese. Especially, most managerial and policy making positions are taken by Chinese which further resulted in deficiency in information flow and constitution of global management policies.

Basing on the conclusions of this research and the researchers 10 years' practices in the cross culture management, following advices which has been successfully carried out in practice are presented.

\section{Publicity of Corporate Image and Culture}

Recruitment channels are the best platform for CB-MNCs to publicize its brand and image. Through the recruitment channels, the CB-MNCs can propagate the mission, strategy, value and industrial positions of the company to its potential candidates. At the mean time, establish joint lab with universities and fund for scholarship programs of universities not only effectively publicizes company brand and image, but also serves to attract potential talents from university graduates. This is especially important for high-tech companies which continuously need new blood as sources of innovation.

Propagation of corporate culture to subsidiaries and branches as well as building and development of sub-cultures in branches are important. Through these measures, foreign employees can receive a better understanding of the CB-MNC's image, mission and strategy and hence form stronger OID with the company, which further helps to form stronger organization commitment and job satisfaction.

\section{Standardization of Internal Management System}

To improve the cross culture work environment and cross culture capability of the CB-MNC, following measures are proposed:

- English-lize all internal management regulations and procedures;

- All information flows are presented on IT based platform (with IT platform also be English-lized);

- Establish of Job Rotation System for foreign employees to work in China, together with reasonable and legitimate compensation and benefit package;

- Establish such human resource systems which are eligible for foreign employees such as position system and leadership development system etc.

\section{Formation of Job Role and Career Development}

Establish a complete training system for foreign employees, including INEO (International New Employee Orientation), OJT (on-job training) and job rotation. These measures will effectively help foreign staff to understand the corporate strategy, culture and internal management procedures and 
regulations, as well as the development of knowledge and skills necessary for accomplishing their job tasks.

\section{The On Target Earning System}

By the On Target Earning System (OTES), foreign employees are provided the chance to clarify their job description, job targets and resources and tools necessary for them to accomplish their tasks. The OTES also defines clearly all the monetary as well as non-material compensations for their effort. The OTES is helpful for foreign staff to set up job role which helps them to direct their efforts to be consistent with the aims of the company.

\section{Cross Culture and leadership Training for Expatriates}

Expatriates, especially expatriates with managerial positions not only serve as the transmitter of corporate strategy and performance targets, but also as the carrier of corporate culture and knowledge. Effective cross culture and leadership training will be helpful for the expatriates to better serve these roles, which will contribute to better work performance, employee engagement and job satisfaction of foreign staff.

\section{REFERENCES}

Alexander, J. (2002). Organizational diagnostics: integrating qualitative and quantitative methodology. Journal of Organizational Change Management, Vol. 15 No.2, pp. 156-168.

Ashforth, B. E., \& Mael, F. (1989). Social identity theory and the organization. Academy of Management Review, 14, 20-39. 150.

Burke, P. J. (1997). An identity model for network exchange. American Sociological Review, 62, 134-

Cheney, G. (1983). On the various and changing meanings of organizational membership: a field study of organizational identification. Communication Monographs, 50, 342-362.

Dutton, J. E., \& Dukerich, J. M. (1991). Keeping an eye on the mirror: image and identity in organizational adaptation. Academy of Management Journal, 34, 517-554.

Dutton, J. E., Dukerich, J. M., \& Harquail, C. V. (1994). Organizational images and member identification. Administrative Science Quarterly, 39, 239-263.

Foreman, P., \& Whetten, D. A. (2002). Members' Identification with Multiple-Identity Organizations. Organization Science, Vol. 13, No. 6. pp. 618-635.

Gallois, C., Tluchowska, M., Callan, V. J. (2001). Communicating in times of uncertainty: The role of nested identities in the assessment of the change process. Paper presented to the Organizational Communication Division at the May, 2001 International Communication Association Conference, Washington, DC.

Hofstede, G. (1980). Culture's consequences: International differences in work-related values. Beverly Hills, CA: Sage Publications.

Jordan, A. (2010). The Importance of Business Anthropology: Its Unique Contributions. International Journal of Business Anthropology, 1(1), pp. 3-14.

Jordan, A. (2003). Business Anthropology: Prospect Heights, Illinois: Waveland Publishers.

Kirkman, B.L., et. al. (2001). Assessing the incremental validity of team consensus ratings over aggregation of individual level data in predicting team effectiveness. Personnel Psychology, 54(3): 645667.

Morgan, J. M. et al. (2004). Tales from the fields: sources of employee identification in Agribusines. Management Communication Quarterly: McQ; 17, 3; ABI/INFORM Global, pg. 360.

Pratt, M. G. (1998). To be or not to be: Central questions in organizational identification. In D. A. Whetten \& P. Godfrey (Eds.), Identity in organizations: Developing theory through conversations. Thousand Oaks, CA: Sage. pp. 171-207. 
Reger, R. K., et. Al. (1994). Reframing the organization: Why implementing total quality is easier said than done. Academy of Management Review, 19.

Roberts, K. H. (1970). On looking at an elephant: An evaluation of cross-cultural research related to organizations. In Weinshall, T. (ed.) Culture and management: Selected readings. Harmondsworth, UK: Penguin, pp.56-104. First published in Psychological Bulletin 74(5):327-50.

Sivakumar, K. and Nakata, C. (2001). The stampede toward Hofstede's framework: avoiding the sample design pit in cross-cultural research. Journal of International Business Studies, 32(3): 555-574.

Stryker, S., \& Serpe, R.T. (1982). Commitment, identity salience, and role behavior: A theory and research example. In Ickes, W. \& Knowles, E.S. (Eds.), Personality, roles, and social behavior, New York: Springer-Verlag, pp. 199-218.

Tajfel, H. (1982). Social psychology of intergroup relations. Annual Review of Psychology, 33, 1-39.

Tian, R., M. Lillis, and A. van Marrewijk (2010), General Business Anthropology, Miami, Fl: North American Business Press.

Usunier, J. C. (1998). International and cross-cultural management research. London: Sage Publications.

Van Marrewijk, A. (2010). European Development in Business Anthropology. International Journal of Business Anthropology. Vol.1 (1), pp. $26-45$

Whetten, D. A., Lewis, D., and Mischel. L. J. (1992). Towards an integrated model of organizational identity and member commitment. Paper presented at the Academy of Management, Las Vegas, NV.

Yan Yan, (2011). A Research on the Structure of Identity-based Organizational Identification. Proceedings of the Third International Symposium on Regional Management Science and Engineering. ST. PLUM-BLOSSOM PRESS, Melbourne, Australia, May, 2011, 214-221. 